\title{
Creep-Fatigue Interaction for SUS 316 Stainless Steel under Combined Loading Conditions*
}

\author{
By Koichi YAGI,** Chiaki TANAKA,** Kiyoshi KUBO ${ }^{* *}$ and \\ Osamu KANEMARU**
}

\begin{abstract}
Synopsis
Combined creep-fatigue loading tests were carried out for SUS 316 stainless steel at 550,650 and $750^{\circ} \mathrm{C}$, in order to examine the effect of testing conditions on the rupture life and the fracture modes. Time to rupture under combined creep-fatigue loadings decreased with increase of the number of cycles of fatigue loading in one block of combined creepfatigue loading schedule. The creep damage $\left(\phi_{c}\right)$ and the fatigue damage $\left(\phi_{f}\right)$ which were accumulated to the rupture of a specimen under combined creep-fatigue loadings were calculated using the linear life fraction damage rule. The rupture life under combined creep-fatigue loadings at $550^{\circ} \mathrm{C}$ was evaluated to be strongly affected by $\phi_{c}$ and $\phi_{f}$ and the relation between $\phi_{c}$ and $\phi_{f}$ was represented by the equation, $\phi_{c}+\phi_{f} \ll 1$. The rupture life at $6500^{\circ} \mathrm{C}$ was evaluated to be determined by the accumulation of either $\phi_{c}$ or $\phi_{f}$. The rupture life at $750^{\circ} \mathrm{C}$ was evaluated to be affected by $\phi_{c}$ and $\phi_{f}$ and the relation between $\phi_{c}$ and $\phi_{f}$ was expressed by $\phi_{c}+$ $\phi_{f} \fallingdotseq 1$.

The specimens tested under combined creep-fatigue loadings at $550{ }^{\circ} \mathrm{C}$ were intergranularly fractured by formation of wedge-type intergranular cracks. Those at $650^{\circ} \mathrm{C}$ were transgranularly fractured with striation under the condition of $\phi_{c}<\phi_{f}$. Those at $750^{\circ} \mathrm{C}$ were intergranularly fractured by the formation of cavity-type intergranular cracks at the interface between matrix and $\mathrm{M}_{23} \mathrm{C}_{6}$ or sigma phase on the grain boundaries.

The fracture modes of the specimens ruptured in constant loading creep tests were examined. The intergranular damage modes under combined creep-fatigue loadings corresponded to those which were obtained from constant loading creep tests under the condition of creep loading (temperature and creep stress) in combined creep-fatigue loading test. It is expected from these results that the same relation between $\phi_{c}$ and $\phi_{f}$ would be obtained, if the combined creep-fatigue loading test is carried out under the condition of creep loading where the same intergranular damage mode, i.e., the same creep fracture mode is observed.
\end{abstract}

\section{Introduction}

The structural materials in high temperature plants are frequently used under the complicated conditions including varying loading. The understanding of the behavior of materials under such varying loadings is considered to be one of the most important subjects for designing and maintaining components, and establishing safety and reliability of components. ${ }^{1)}$

The service conditions at the heated surfaces of heavy components can be simulated by varying loadings for which creep loading and fatigue loading are alternatively repeated..$^{2-5}$ ) It is considered in this loading condition that the fatigue loading corresponds to the cyclic loading resulted from temperature change accompanied with start-up and shut-down of plant, and the creep loading corresponds to the residual stress resulted from the cyclic loading during start-up and the static loading in service. Such a combined creep-fatigue loading test method has the advantage that creep damage and fatigue damage can be directly and easily evaluated by the linear life fraction damage rule. A long term creep-fatigue behavior can be readily and inexpensively examined, if the creep loading test in combined creep-fatigue loading test is carried out using a creep testing machine. The material behavior under varying loadings and the influence of creep damage and fatigue damage on rupture life should be investigated using this combined creep--fatigue loading test method. However, there are few reports about the material behavior under combined creep-fatigue loading conditions, ${ }^{3-6)}$ and there still remains many problems to solve the damage processes, damage evaluation and creep-fatigue interaction under these conditions.

The authors are investigating to clarify the effects of creep damage and fatigue damage on rupture life under combined creep-fatigue loadings, and to establish the method of damage evaluation and life prediction. ${ }^{7-9)}$ In this paper, the combined creep-fatigue loading tests with various testing factors are applied for SUS 316 stainless steel, and the effects of the testing conditions on rupture life are examined. Further, the effect of creep damage on rupture life is examined by observing fracture surface and microstructure, and the relation between rupture life under combined creep-fatigue loadings and creep fracture mode conditions is discussed from metallographical viewpoint.

\section{Material and Testing Procedures}

\section{Material and Specimens}

The material tested was of SUS 316 stainless steel plate with the thickness of $24 \mathrm{~mm}$. The chemical composition is shown in Table 1. The steel was

Table 1. Chemical composition of material. (wt \%)

\begin{tabular}{ccccccccccccccc}
\hline $\mathrm{C}$ & $\mathrm{Si}$ & $\mathrm{Mn}$ & $\mathrm{P}$ & $\mathrm{S}$ & $\mathrm{Gu}$ & $\mathrm{Cr}$ & $\mathrm{Ni}$ & $\mathrm{Mo}$ & $\mathrm{Ti}$ & $\mathrm{Nb}+\mathrm{Ta}$ & $\mathrm{B}$ & $\mathrm{Al}$ & $\mathrm{N}$ \\
\hline 0.05 & 0.70 & 1.10 & 0.034 & 0.003 & 0.31 & 17.05 & 12.60 & 2.24 & 0.03 & 0.001 & 0.003 & $<0.003$ & 0.017 \\
\hline
\end{tabular}

* Partly published in Journal of The Society of Materials Science, Japan, 33 (1984), 1533, in Japanese; formerly presented to the 103rd ISIJ Meeting, April 1982, S653, at Tokyo Institute of Technology in Tokyo, and at the 107th ISIJ Meeting, April 1984, S528, at Chiba Institute of Technology in Narashino. Manuscript received on August 24, 1984; accepted in the final form on May $10,1985$. (C) 1985 ISIJ

** National Research Institute for Metals, Nakameguro, Meguro-ku, Tokyo 153. 
water-quenched after solution treatment for $0.5 \mathrm{~h}$ at $1100{ }^{\circ} \mathrm{C}$. The tensile properties at room temperature, 550, 650 and $750^{\circ} \mathrm{C}$ are listed in Table 2 .

Dimension of the specimen used for combined creep-fatigue loading test and fatigue test was $6 \mathrm{~mm}$ in diameter at parallel portion, and $13.2 \mathrm{~mm}$ in gauge length, with the edges at ends of the parallel portion for extensometer as shown in Fig. 1(a). In order to examine the effect of prior creep damage on fatigue life, the specimen shown in Fig. 1(a) was also remachined from the prior crept large specimen. The large specimen shows in Fig. 1(b). The specimen used for constant loading creep test was $10 \mathrm{~mm}$ in diameter and $50 \mathrm{~mm}$ in gauge length. It was assumed that the time to rupture under constant creep loading for the former specimen shown in Fig. 1(a) was little different from that for the latter specimen with diameter of $10 \mathrm{~mm} .{ }^{10}$ ) The specimens were taken in parallel with the rolling direction of the plate. The portion between the edges of specimens for combined creepfatigue loading test and fatigue test was polished in the longitudinal direction after machining.

\section{Combined Creep-Fatigue Loading Test Method}

The stress-controlled creep loading and the straincontrolled fatigue loading are alternatively repeated in the combined creep-fatigue loading test. The loading schedule of stress and strain, and the hysteresis loops of this test are schematically shown in Fig. 2. The combined loading schedule was continuously repeated till rupture of the specimen. Although there are various methods in the combined loading tests in which creep loading and fatigue loading are re-

Table 2. Tensile properties of material at room temperature, 550, 650 and $750{ }^{\circ} \mathrm{C}$.

\begin{tabular}{c|cccc}
\hline $\begin{array}{c}\text { Temperature } \\
\left({ }^{\circ} \mathrm{G}\right)\end{array}$ & $\begin{array}{c}0.2 \% \\
\text { proof stress } \\
\left(\mathrm{kgf} / \mathrm{mm}^{2}\right)\end{array}$ & $\begin{array}{c}\text { Tensile } \\
\text { strength } \\
\left(\mathrm{kgf} / \mathrm{mm}^{2}\right)\end{array}$ & $\begin{array}{c}\text { Elonga- } \\
\text { tion } \\
(\%)\end{array}$ & $\begin{array}{c}\text { Reduction } \\
\text { of area } \\
(\%)\end{array}$ \\
\hline $\mathrm{RT}$ & 27 & 62 & 58 & 78 \\
550 & 17 & 50 & 39 & 60 \\
650 & 17 & 38 & 54 & 69 \\
750 & 15 & 27 & 65 & 76 \\
\hline
\end{tabular}

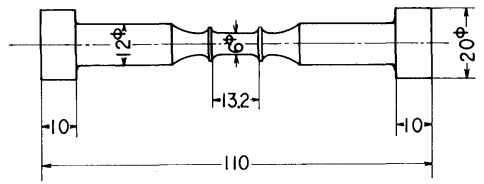

(a) Fatigue specimen

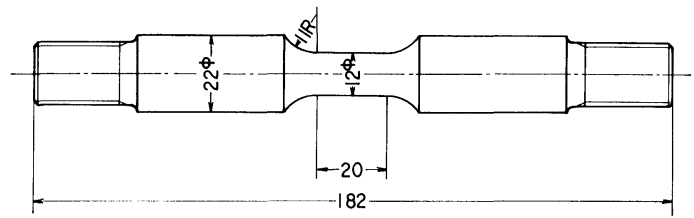

(b) Prior creep specimen

Unit;mm

Fig. 1. Shape and dimension of specimens for combined creep-fatigue loading test and for prior creep loading. peated, ${ }^{4,5,11,12)}$ the loading schedule shown in Fig. 2 was adopted in the present work because of the ability of automatic test and the easiness of control of testing machine. The stress and the strain are reduced to zero at the end of creep loading and fatigue loading in this test. The loading schedule for this test method is similar to that for the testing procedure in MPG.4)

In this test method, the accumulated strain was reduced to zero at the end of creep loading by compressing. Therefore, the behavior for the cyclic loading creep test in which only the creep loadings are repeated without the fatigue loading might not be directly compared with that in constant loading creep test. The rupture time in cyclic loading creep test, however, fairly well agreed with that in constant loading creep test at $650^{\circ} \mathrm{C}$ and for lower stresses on SUS 316 stainless steel. ${ }^{9)}$ It was considered from these results that it was possible to neglect the effect of the compression of creep strain on time to rupture for the conditions of higher temperatures and lower stresses.

The servo-hydraulic testing machines used consist of two function generators for creep loading and fatigue loading, a programming unit by which the loading schedule is controlled, and an elastic strain reset detector by which the stress and the strain can be reduced to zero at the end of both loadings.

\section{Testing Conditions}

The combined creep-fatigue loading tests were carried out under three temperatures 550, 650 and $750{ }^{\circ} \mathrm{C}$. This test method has four testing factors which consist of creep stress $\left(\sigma_{c}\right)$ and creep time $\left(t_{c}\right)$ in creep loading, and total strain range $\left(\Delta \varepsilon_{t}\right)$ and number of cycles $(\mathcal{N})$ in fatigue loading, as shown in Fig. 2. It had been expected from the authors' result that the creep-fatigue interaction under combined loading might be related with the creep fracture modes which were observed for constant loading creep tests under the creep loading condition $\left(\sigma_{c}\right)$ in combined creep-fatigue loading test. ${ }^{9)}$ Three creep fracture

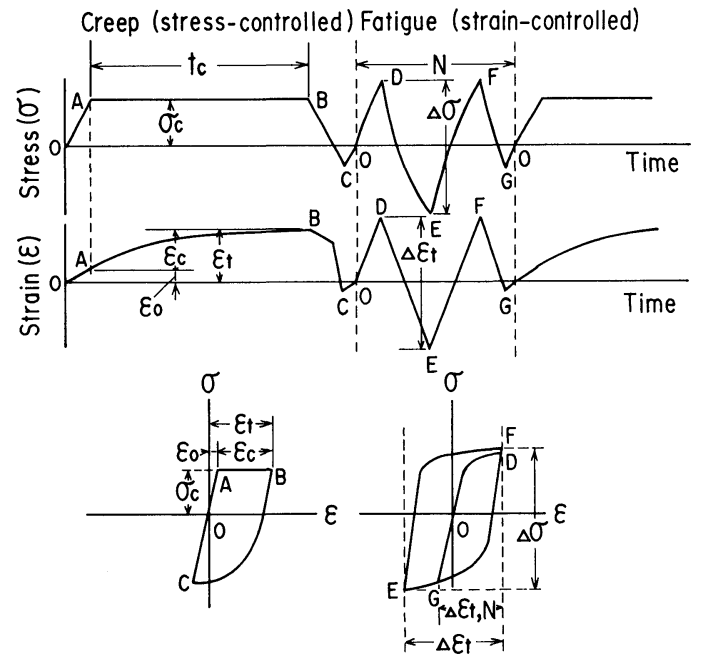

Fig. 2. Loading schedule of stress and strain, and hysteresis loops for combined creep-fatigue loading test. 
modes were observed for the present material: (1) the intergranular fracture due to wedge-type intergranular cracking, (2) the transgranular fracture and (3) the intergranular fracture due to cavity-type intergranular cracking. The value of stress denoted as $\sigma_{c}$ was chosen from these creep fracture modes and the rupture stress of approximately $1000 \mathrm{~h}$ in constant loading creep tests at each temperature. That is, the values of $\sigma_{c}$ were $36 \mathrm{kgf} / \mathrm{mm}^{2}$ at $550{ }^{\circ} \mathrm{C}, 17.5 \mathrm{kgf} / \mathrm{mm}^{2}$ at $650{ }^{\circ} \mathrm{C}$ and $7.5 \mathrm{kgf} / \mathrm{mm}^{2}$ at $750^{\circ} \mathrm{C}$. $t_{c}$ was $10 \mathrm{~h}$ and $\Delta \varepsilon_{t}$ was $1 \%$ in all combined creep-fatigue loading tests. A triangular waveform at a strain rate of $6 \% / \mathrm{min}$ was used in fatigue loadings under strain control. $\mathcal{N}$ was from 2 to 50 cycles.

The constant loading creep test and the straincontrolled fatigue test were carried out in order to obtain the basic data which are compared with the rupture life for combined creep-fatigue loading tests.

In order to clarify the effect of the intergranular creep damages on fatigue life, the prior creep tests followed by fatigue tests were carried out at the same conditions as those in combined creep-fatigue loading tests: $36 \mathrm{kgf} / \mathrm{mm}^{2}$ at $550{ }^{\circ} \mathrm{C}, 17.5 \mathrm{kgf} / \mathrm{mm}^{2}$ at $650^{\circ} \mathrm{C}$ and $7.5 \mathrm{kgf} / \mathrm{mm}^{2}$ at $750^{\circ} \mathrm{C}$. The total strain range in fatigue tests after prior creep loading was $1 \%$. The prior creep tests were interrupted at the time $\left(t_{A}\right)$ of which the ratios to rupture time $\left(t_{R}\right)$ were approximately 0.4 (steady state creep range) and approximately 0.7 (accelerating creep range).

\section{Results}

\section{Results of Combined Creep-Fatigue Loading Tests}

The results of combined creep-fatigue loading tests are shown in Figs. 3 and 4 . Figure 3 shows the comparison of total creep time to rupture in combined creep-fatigue loading tests $\left(\Sigma t_{c}\right)$ with time to rupture in constant loading creep tests. $\Sigma t_{c}$ decreased with increasing $\mathcal{N}$ under fatigue loading. Figure 4 shows the comparison of total number of cycles to rupture in combined creep-fatigue loading tests $(\Sigma \mathcal{N})$ with the results in strain-controlled fatigue tests. Although the strain range at $\mathcal{N}$-th cycle in fatigue loading of combined creep-fatigue loading test is not $1 \%, \mathcal{N}$-th cycle was counted as one cycle for this figure. $\Sigma \mathcal{N}$ decreased with decreasing $\mathcal{N}$ under fatigue loading. It should be noted in Fig. 3 that $\Sigma t_{c}$ at $650{ }^{\circ} \mathrm{C}$ did not depend on $\mathcal{N}$ less than 10 cycles and was almost equal to rupture time in constant loading creep tests. The specimens in combined creep-fatigue loading test at $550{ }^{\circ} \mathrm{C}$ fractured near the edge of specimen except one specimen for $\mathcal{N}=15$ cycles. All specimens in combined creep-fatigue loading test at 650 and $750{ }^{\circ} \mathrm{C}$ fractured near middle of the gauge length. Most specimens in fatigue test at each temperature fractured near the edge.

The creep strain under creep loading $\left(\varepsilon_{c}\right)$ and the maximum stress range under fatigue loading $\left(\Delta \sigma_{\max }\right)$ in each block of combined creep-fatigue loading tests at $750{ }^{\circ} \mathrm{C}$ are shown in Fig. 5. $\varepsilon_{c}$ increased gradually, and then rapidly before rupture. On the other hand, $\Delta \sigma_{\max }$ decreased up to second to third block, and then

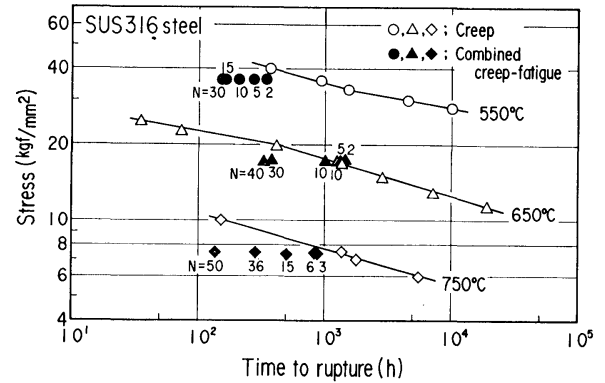

Fig. 3. Comparison of time to rupture under combined creep-fatigue loadings with that under constant loadings.

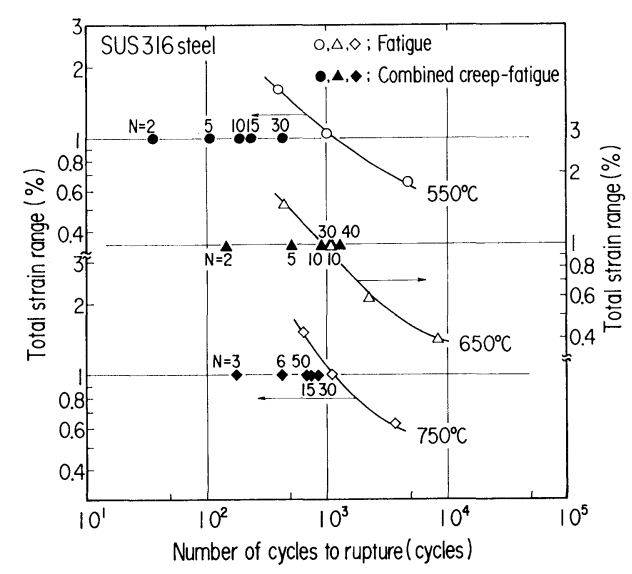

Fig. 4. Comparison of number of cycles to rupture under combined creep-fatigue loadings with that under strain controlled fatigue loadings.

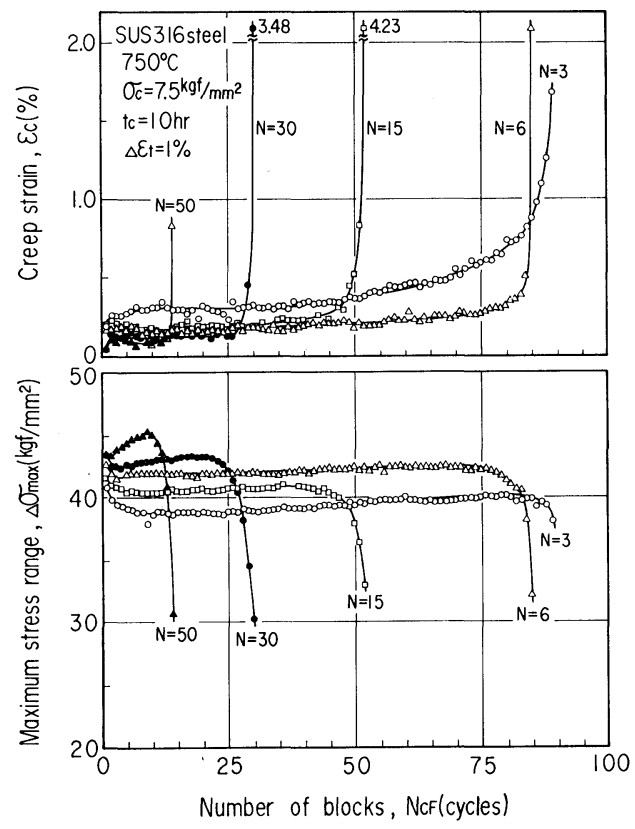

Fig. 5. Creep strain under creep loading and maximum stress range under fatigue loading in combined creep-fatigue loading tests at $750^{\circ} \mathrm{C}$.

became constant, followed by a large decrease immediately before rupture. The number of block $\left(\mathcal{N}_{C F}\right)$ at which $\varepsilon_{c}$ increased rapidly was nearly the same as that at which $\Delta \sigma_{\max }$ decreased rapidly. The 
behavior of $\varepsilon_{c}$ and $\Delta \sigma_{\max }$ showed the same tendency at different temperatures. Although it is presumed that this value of $\mathcal{N}_{C F}$ corresponds to the formation of macrocrack, this fact will be investigated as future problems on the damage processes under combined creep-fatigue loadings. The value of $\Delta \sigma_{\max }$ at the steady state in combined creep-fatigue loading tests was nearly equal to the maximum stress range which was measured for this cyclically hardened material in strain-controlled fatigue tests.

\section{Metallographic Observations}

Fracture surface of the specimens which were tested under combined creep-fatigue loadings were observed using a scanning electron microscope. Sharp intergranular facets were observed in the specimens ruptured at $550^{\circ} \mathrm{C}$. Although it was difficult to distinguish the types of fracture modes because the fracture surfaces at 650 and $750{ }^{\circ} \mathrm{C}$ were oxidized, the fracture surfaces at these temperatures were characterized by more round and uneven facets. The typical intergranular fracture surfaces observed at 550, 650 and $750{ }^{\circ} \mathrm{C}$ are shown in Photos. 1(a), 2(a) and 3(a), respectively.

The microstructures and microcracks in the specimens ruptured were observed. The typical results are represented in Photos. 1(b), 2(b) and 3(b). A wedge-
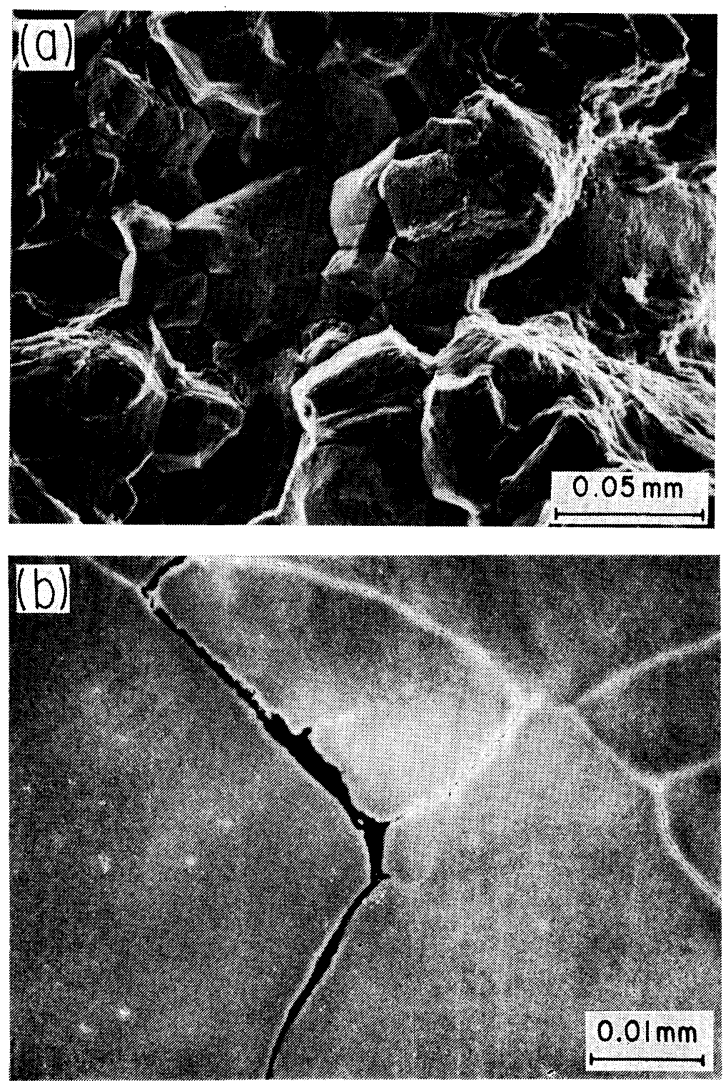

(a) Fracture surface

(b) Microstructure

Photo. 1. Scanning electron microfractographs of specimen ruptured in combined creep-fatigue loading test at 550 ${ }^{\circ} \mathrm{C}, \sigma_{c}=36 \mathrm{kgf} / \mathrm{mm}^{2}, t_{c}=10 \mathrm{~h}, \Delta \varepsilon_{t}=1 \%, \mathcal{N}=2$ cycles, $\phi_{c}=0.35$, and $\phi_{f}=0.05$. type intergranular crack was observed in the specimens ruptured at 550 and $650{ }^{\circ} \mathrm{C}$ as shown in Photos. 1(b) and 2(b). An intergranular cavity was seen at the interface between matrix and carbide $\left(\mathrm{M}_{23} \mathrm{C}_{6}\right)$ or sigma phase in the specimens ruptured at $750^{\circ} \mathrm{C}$, as shown in Photo. 3(b).

The relations between the results of these metallographic observations and the testing conditions were examined. For the specimens ruptured at $550{ }^{\circ} \mathrm{C}$, the intergranular fracture was observed when $\mathcal{N}$ was small, but the transgranular fracture with striation was also observed with increase of $\mathcal{N}$. The wedgetype intergranular cracks were seen in every specimen tested at $550{ }^{\circ} \mathrm{C}$. From these metallographic observations, the fracture under the condition of small $\mathcal{N}$ at $550{ }^{\circ} \mathrm{C}$ was considered to be related with the intergranular damages due to growth and interlinking of wedge-type intergranular cracks. For the specimens ruptured at $650{ }^{\circ} \mathrm{C}$, the transgranular fracture with striation was observed in the case of $\mathcal{N}$ more than 10 cycles. The intergranular fracture observed in the case of $\mathcal{N}$ less than 10 cycles at $650{ }^{\circ} \mathrm{C}$ was considered to be due to growth and interlinking of wedge-type intergranular cracks. For the specimens ruptured at $750{ }^{\circ} \mathrm{C}$, the transgranular cracking with striation was partly seen only in the case of $\mathcal{N}=50$ cycles, and the cavity-type cracking was observed
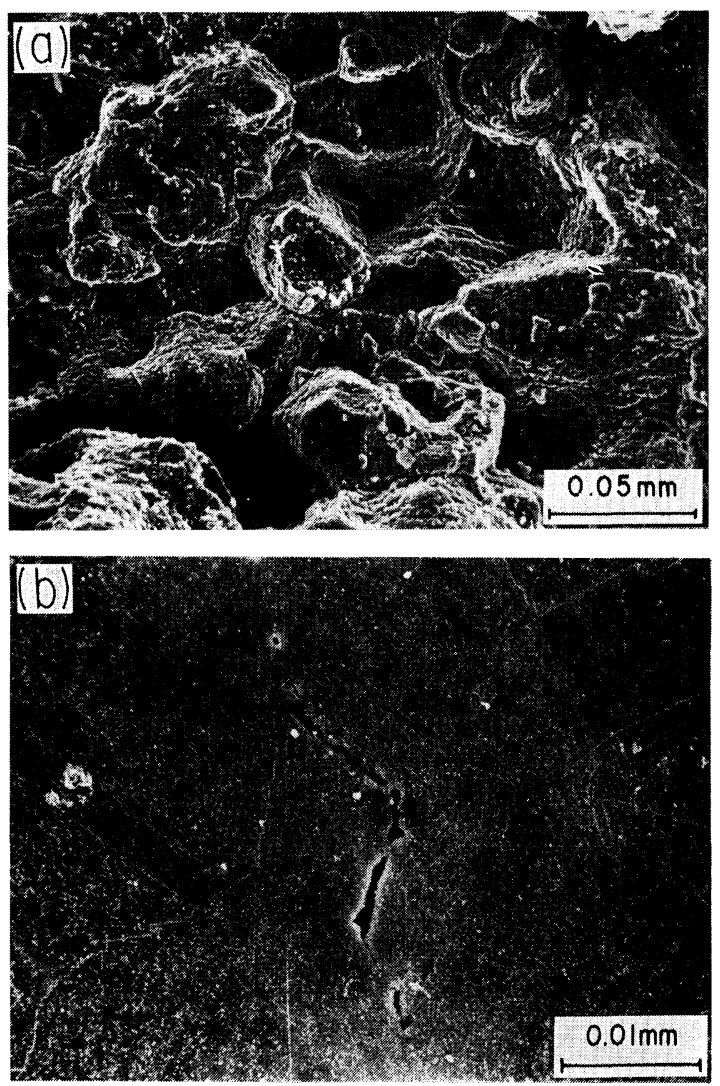

(a) Fracture surface

(b) Microstructure

Photo. 2. Scanning electron microfractographs of specimen ruptured in combined creep-fatigue loading test at 650 ${ }^{\circ} \mathrm{C}, \sigma_{c}=17.5 \mathrm{kgf} / \mathrm{mm}^{2}, t_{c}=10 \mathrm{~h}, \Delta \varepsilon_{t}=1 \%, \mathcal{N}=5 \mathrm{cy}-$ cles, $\phi_{c}=1.31$, and $\phi_{f}=0.64$ 
under every condition. The fracture at $750{ }^{\circ} \mathrm{C}$ was considered to be related with the intergranular damages due to growth and interlinking of cavities.

The cracks of the specimens ruptured in straincontrolled fatigue tests for $\Delta \varepsilon_{t}=1 \%$ were considered from the metallographic observations to be nucleated at the surface and then propagated transgranularly from the surface.

\section{Effects of Prior Creep Damage on Fatigue Life}

The fatigue tests were carried out by using a triangular waveform at strain range of $1 \%$ and strain rate of $6 \% / \mathrm{min}$ for the prior crept materials. The results are shown in Fig. 6. For the materials crept at $550{ }^{\circ} \mathrm{C}$, the number of cycles to fracture in fatigue tests decreased with increasing the ratio of prior creep time $\left(t_{A}\right)$ to rupture time $\left(t_{R}\right)$ in constant loading creep test. For the materials crept at $650{ }^{\circ} \mathrm{C}$, the number of cycles to fracture in fatigue tests increased with $t_{A} /$ $t_{R}$. The number of cycles to fracture at $750^{\circ} \mathrm{C}$ increased and subsequently decreased with $t_{A} / t_{R}$. It is reported that the fatigue life increased for the thermal aged materials and decreased for the creep damaged materials of SUS 316 stainless steel. ${ }^{13)}$

The fracture surface of the specimens ruptured in fatigue tests for the prior crept materials was examined. The fraction of intergranular facet on the fracture sur-
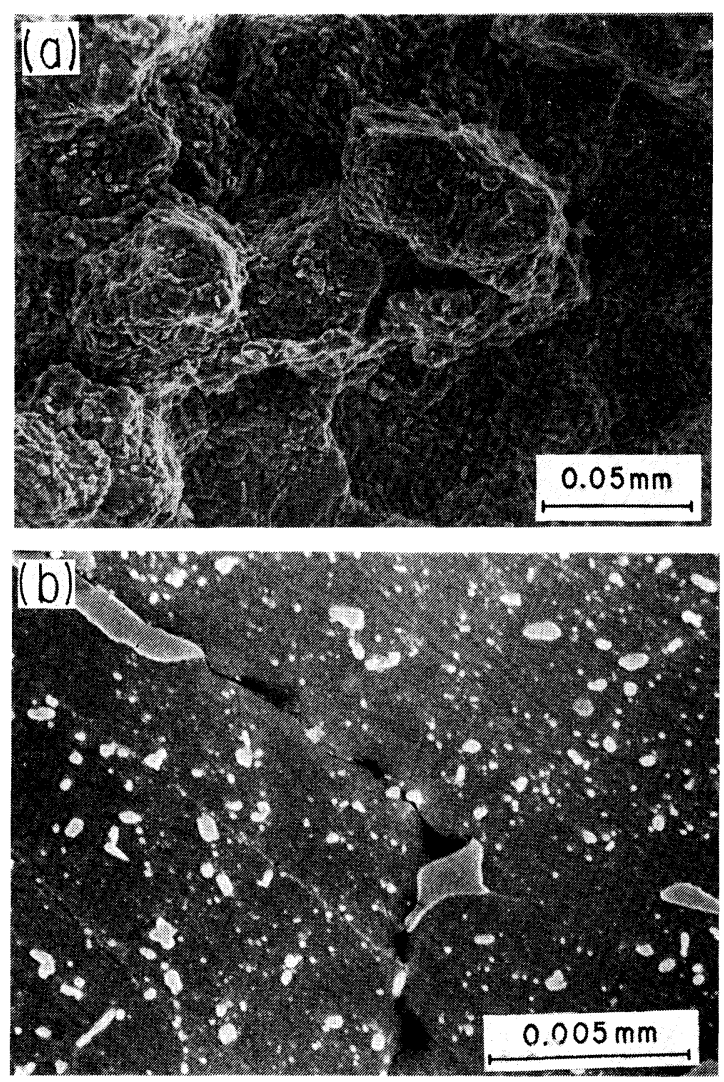

(a) Fracture surface

(b) Microstructure

Photo. 3. Scanning electron microfractographs of specimen ruptured in combined creep-fatigue loading test at 750 ${ }^{\circ} \mathrm{C}, \quad \sigma_{c}=7.5 \mathrm{kgf} / \mathrm{mm}^{2}, t_{c}=10 \mathrm{~h}, \Delta \varepsilon_{b}=1 \%, \mathcal{N}=3 \mathrm{cy}-$ cles, $\phi_{c}=0.79$, and $\phi_{f}=0.17$. face of specimens ruptured in fatigue tests was measured using a point counting method. The experimental results are shown in Fig. 7. The fraction of intergranular facet rapidly increased at $t_{A} / t_{R}$ exceeding 0.6 for the materials crept at 550 and $750{ }^{\circ} \mathrm{C}$, but the intergranular facets were hardly seen over the value of $t_{A} / t_{R}$ of 0.8 for the materials crept at $650{ }^{\circ} \mathrm{C}$. The fact means that the grain boundaries for materials crept at 550 and $750{ }^{\circ} \mathrm{C}$ were subjected to the creep damages which decreased the fatigue life, but the grain boundaries for materials crept at $650{ }^{\circ} \mathrm{C}$ were little subjected to the creep damages.

\section{Discussion}

\section{Evaluation of Damages Using a Linear Life Fraction Damage Rule}

The creep damage $\left(\phi_{c}\right)$ and the fatigue damage $\left(\phi_{f}\right)$ which were accumulated till rupture of the specimen in combined creep-fatigue loading tests were calculated using the linear life fraction damage rule ${ }^{14)}$ as follows:

$$
\begin{array}{r}
\phi_{c}=\frac{\mathcal{N}_{c} t_{c}}{t_{R}} \ldots \ldots \ldots \\
\phi_{f}=\mathcal{N}_{c}\left(\frac{\mathcal{N}-1}{\mathcal{N}_{f}}+\frac{1}{\mathcal{N}_{f f}}\right)
\end{array}
$$

where, $\mathcal{N}_{c}$ : the number of blocks to rupture under combined creep-fatigue loadings

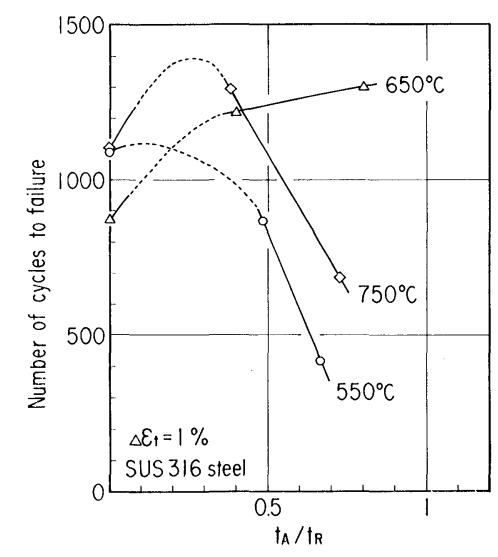

$t_{\Lambda}:$ prior creep time

$t_{R}: \quad$ creep rupture time

Fig. 6. Effects of prior creep loading on number of cycles to rupture in fatigue test.

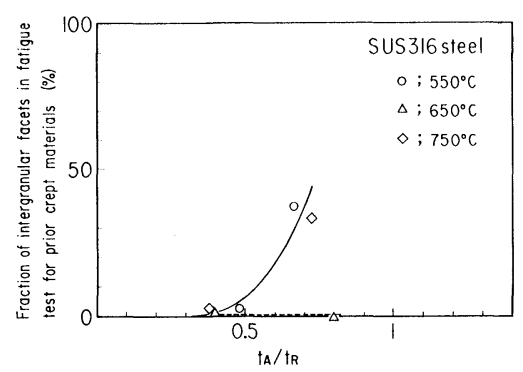

Fig. 7. Effects of prior creep loading on fraction of intergranular facets in fatigue test. 
$t_{R}$ : the time to rupture in a constant loading creep test at the value of $\sigma_{c}$

$\mathcal{N}_{f}$ : the number of cycles to rupture in a strain-controlled fatigue test at the value of $\Delta \varepsilon_{t}$

$\mathcal{N}_{f f}$ : the number of cycles to rupture in a fatigue test at the strain range, $\Delta \varepsilon_{t, N}$, shown in Fig. 2.

$\Delta \varepsilon_{t, N}$ corresponds to the strain range at $\mathcal{N}$-th cycle in fatigue loading of combined creep-fatigue loading test. The value of $t_{R}, \mathcal{N}_{f}$ and $\mathcal{N}_{f f}$ were obtained from the results of constant loading creep tests and straincontrolled fatigue tests shown in Figs. 3 and 4.

Figure 8 shows the relation between $\phi_{c}$ and $\phi_{f}$ calculated using the Eqs. (1) and (2) from the results of combined creep-fatigue loading tests at 550, 650 and $750{ }^{\circ} \mathrm{C}$. The relation between $\phi_{c}$ and $\phi_{f}$ was dependent on testing temperatures. The rupture life under combined creep-fatigue loadings at $550{ }^{\circ} \mathrm{C}$ is strongly affected by creep damage and fatigue damage, and the relation between the two damages is expressed by $\phi_{c}+\phi_{f} \ll 1$. The rupture life at $650{ }^{\circ} \mathrm{C}$ is determined by the accumulation of either creep damage or fatigue damage. The rupture life at $750{ }^{\circ} \mathrm{G}$ is affected by creep damage and fatigue damage, and the relation between the two damages is expressed by $\phi_{c}+\phi_{f} \fallingdotseq 1$.

The creep damage subjected to prior creep loadings and the fatigue damage subjected to fatigue loadings for the prior crept materials are calculated as follows:

$$
\begin{gathered}
\phi_{c}=\frac{t_{A}}{t_{R}} \\
\phi_{f}=\frac{\mathcal{N}_{A f}}{\mathcal{N}_{f}}
\end{gathered}
$$

where, $\mathcal{N}_{A f}$ : the number of cycles to rupture in fatigue test at $\Delta \varepsilon_{t}$ of $1 \%$ for the prior crept materials.

The results calculated are shown by the soild symbols in Fig. 8. The relations between $\phi_{c}$ and $\phi_{f}$ obtained from the results of fatigue tests for the prior crept materials show the same trends as the relations obtained from the results of combined creep-fatigue loading tests. It is considered that the influence of

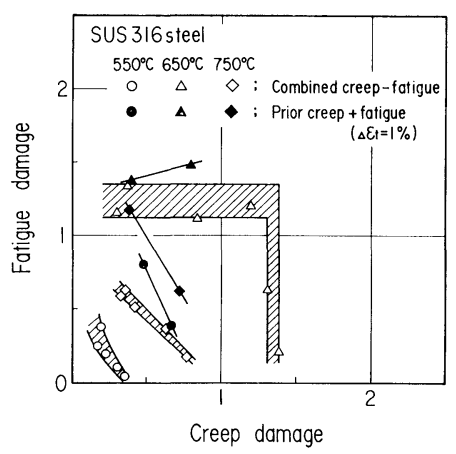

Fig. 8. Relations between creep damage $\left(\phi_{c}\right)$ and fatigue damage $\left(\phi_{f}\right)$ calculated concerning the rupture life under combined creep-fatigue loadings and under prior creep loading and fatigue loading using the linear life fraction damage rule. intergranular damage modes on the rupture life is same in both testing procedures, because the fracture modes observed in the combined creep-fatigue loading tests correspond to those observed in the fatigue tests for the prior crept materials. The difference between the relation of $\phi_{c}$ and $\phi_{f}$ at $550{ }^{\circ} \mathrm{C}$ and that at $750{ }^{\circ} \mathrm{C}$ is considered to be due to the difference of intergranular damage modes, that is, the wedge-type intergranular cracking at $550{ }^{\circ} \mathrm{C}$ and the cavity-type intergranular cracking at $750^{\circ} \mathrm{C}$. The less severe creep-fatigue interaction under fatigue loadings for the prior crept materials than that under combined creep-fatigue loadings seems to be due to the elimination of surface creep cracks by re-machining of the specimens after the prior creep loadings.

It is concluded from the evaluation of results using the linear life fraction damage rule and the metallographic observations that the strong influence of creep damage and fatigue damage on rupture life under combined creep-fatigue loadings at $550{ }^{\circ} \mathrm{C}$ is caused by the formation of wedge-type intergranular cracks under creep loadings, the influence of both damages at $750{ }^{\circ} \mathrm{C}$ is caused by the formation of cavity-type intergranular cracks, and cumulative influence of creep damage and fatigue damage at $650{ }^{\circ} \mathrm{C}$ is caused by the absence of intergranular cracks under this condition.

\section{Creep Fracture Modes}

It was clarified that the influence of creep damage and fatigue damage on rupture life under combined creep-fatigue loadings was related with the formation of intergranular cracks. Considering that the wedgetype intergranular cracks and the cavity-type intergranular cracks observed are formed by the intergranular damages under creep loadings, the creep fracture modes of the specimens ruptured in constant loading creep tests are examined, and three types of fracture modes are recognized from the metallographic observations as follows;

1) the intergranular fracture due to formation and growth of wedge-type intergranular cracks (Wtype)

2) the transgranular fracture (T-type)

3) the intergranular fracture due to formation and growth of cavities at the interface between matrix and $\mathrm{M}_{23} \mathrm{C}_{6}$ or sigma phase on the grain boundaries (C-type).

Figure 9 shows the regions of the creep fracture modes in constant loading creep tests which are classified into the above three types. The fracture mode is of W-type at higher stresses below $550{ }^{\circ} \mathrm{C}$, C-type at lower stresses above $650{ }^{\circ} \mathrm{C}$, and T-type at the stress and temperature between these conditions. The values of stress given in this figure are the creep loading stress $\left(\sigma_{c}\right)$ in the combined creep-fatigue loading test at each temperature.

The intergranular fracture mode due to the formation of wedge-type crack which was observed at higher stresses below $550{ }^{\circ} \mathrm{C}$ was then examined. A specimen was rapidly cooled to room temperature under loading after creep straining to the steady state creep 


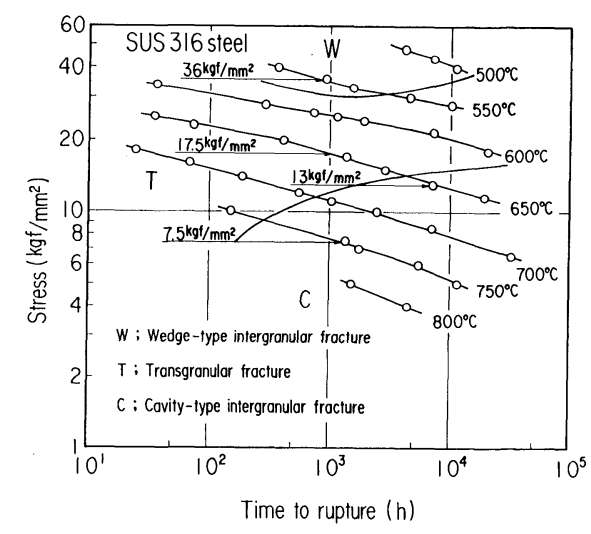

Fig. 9. Creep fracture modes in constant loading creep tests for SUS 316 stainless steel, and creep stresses in combined creep-fatigue loading tests.

$(360 \mathrm{~h})$ at $550{ }^{\circ} \mathrm{C}$ and at $36 \mathrm{kgf} / \mathrm{mm}^{2}$, and the tensile test was conducted on this specimen at room temperature at a strain rate of $3.6 \% / \mathrm{min}$. The specimen exhibited a significant yield drop, which was not seen for the solution treated material, as shown in Fig. 10, providing the evidence of strain aging due to dislocation locking possibly occured during creep under this condition. ${ }^{15,16)}$ The matrix crept at $550{ }^{\circ} \mathrm{C}$ was hardened by strain aging. It is imagined that the stress produced by grain boundary sliding concentrates at triple point, but the stress hardly relaxes in the hardened matrix. The wedge-type crack nucleates at the point where the stress concentrates enough. ${ }^{17)}$ It is, thus, concluded that the intergranular fracture due to the wedge-type cracks at higher stresses below $550{ }^{\circ} \mathrm{C}$ is caused by hardening of the matrix due to strain aging occurred during creep.

\section{Relation between Creep-Fatigue Interaction and Creep Fracture Modes}

The relation between the condition of creep loading (temperature and $\sigma_{c}$ ) in combined creep-fatigue loading test and the creep fracture mode in constant loading creep tests shown in Fig. 9 was examined. The creep stress in combined creep-fatigue loading tests at 550,650 and $750{ }^{\circ} \mathrm{C}$ corresponded to the Wtype region, $\mathrm{T}$-type region and $\mathrm{C}$-type region in this figure, respectively.

The increase of stress range with increase of the number of cycles in strain-controlled fatigue tests at $550{ }^{\circ} \mathrm{C}$ is reported to be due to strain aging. ${ }^{18)}$ It is assumed that the matrix under combined creepfatigue loadings at $550{ }^{\circ} \mathrm{C}$ is also hardened by strain aging because $\Delta \sigma_{\max }$ at the steady state in combined creep-fatigue loading tests is almost equal to the maximum value of stress range in strain-controlled fatigue test. Therefore, it is suggested that the wedge-type intergranular cracking under combined creep-fatigue loadings at $550{ }^{\circ} \mathrm{C}$ is related to matrix strengthening due to dislocation locking in the same manner as the fracture mode in constant loading creep tests.

The intergranular fracture due to the formation of cavities at the interface between matrix and $\mathrm{M}_{23} \mathrm{C}_{6}$ or

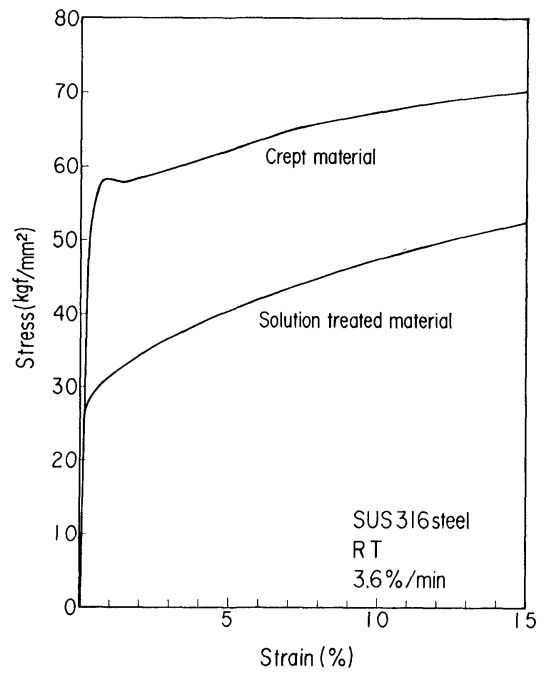

Fig. 10. Comparison of tensile behavior at room temperature for the material crept at $550{ }^{\circ} \mathrm{C}$ and $36 \mathrm{kgf}$ / $\mathrm{mm}^{2}$ with that for the solution treated material.

sigma phase on the grain boundaries was observed under combined creep-fatigue loadings at $750{ }^{\circ} \mathrm{C}$ as well as in constant loading creep tests at $750^{\circ} \mathrm{C}$. It was found from the metallographic examinations that the intergranular damage in combined creep-fatigue loading tests at $750^{\circ} \mathrm{C}$ was the same as that in constant loading creep tests.

It is expected from these considerations that the relation between $\phi_{c}$ and $\phi_{f}$ under combined creepfatigue loadings becomes $\phi_{c}+\phi_{f} \ll 1$ in the case of the creep loading condition of W-type region in Fig. 9, the rupture life is determined by the accumulation of either $\phi_{c}$ or $\phi_{f}$ in the case of the condition of T-type and the relation between $\phi_{c}$ and $\phi_{f}$ becomes $\phi_{c}+\phi_{f} \fallingdotseq 1$ in the case of the condition of C-type. In addition, many examinations for other materials and the analyses of damage processes under creep-fatigue interaction should be made in order to verify this expectation.

Although the fracture mode in the constant loading creep tests at $650{ }^{\circ} \mathrm{C}$ for the stresses where the combined creep-fatigue loading tests were carried out was transgranular, it was intergranular in combined creep-fatigue loading tests under the condition of $\phi_{c}>\phi_{f}$ due to formation of wedge-type intergranular cracks. The fracture mode in cyclic loading creep tests in which only the creep loading of combined creep-fatigue loading test was alternatively repeated was examined at $650{ }^{\circ} \mathrm{C}$. In the case of stresses higher than $17 \mathrm{kgf} / \mathrm{mm}^{2}$, the transgranular fracture was observed in constant loading creep tests, but the intergranular fracture due to the wedge-type intergranular cracking was observed in cyclic loading creep tests. The creep strain in cyclic loading creep tests was suppressed and reduced to zero after each creep loading, as shown in Fig. 2. It is highly conceivable that the difference in fracture modes between the combined creep-fatigue loading tests and the constant loading creep tests comes from the difference in the two loading schedules. 


\section{Conclusions}

The combined creep-fatigue loading tests were carried out for SUS 316 stainless steel at 550, 650 and $750{ }^{\circ} \mathrm{C}$, and the effect of the testing conditions on rupture life and fracture modes was examined. The relations between the creep-fatigue interaction under combined loadings and the creep fracture mode conditions were discussed. The results are summarized as follows:

(1) The time to rupture under combined creepfatigue loadings decreased with increasing the number of cycles in fatigue loading $(\mathcal{N})$ in one block of combined creep-fatigue loading schedule, and the total number of cycles to rupture decreased with decreasing $\mathcal{N}$.

(2) The evaluation of the combined creep-fatigue loading tests using the linear life fraction damage rule gave that the rupture life at $550{ }^{\circ} \mathrm{C}$ was strongly affected by creep damage $\left(\phi_{c}\right)$ and fatigue damage $\left(\phi_{f}\right)$ and the relation between $\phi_{c}$ and $\phi_{f}$ was represented by the equation, $\phi_{c}+\phi_{f} \ll 1$, the rupture life at $650^{\circ} \mathrm{C}$ was determined by the accumulation of either $\phi_{c}$ or $\phi_{f}$, and the rupture life at $750{ }^{\circ} \mathrm{C}$ was affected by $\phi_{c}$ and $\phi_{f}$ and the relation between $\phi_{c}$ and $\phi_{f}$ was expressed by $\phi_{c}+\phi_{f} \fallingdotseq 1$. The relations between $\phi_{c}$ and $\phi_{f}$ obtained from the results of fatigue tests for the prior crept materials were also dependent on testing temperatures in the same manner as the relations obtained from the results of combined creep-fatigue loading tests.

(3) The specimens under combined creep-fatigue loadings at $550{ }^{\circ} \mathrm{C}$ were intergranularly fractured by the formation of wedge-type intergranular cracks, those at $650{ }^{\circ} \mathrm{C}$ were intergranularly fractured by the formation of wedge-type intergranular cracks under the condition $\phi_{c}>\phi_{f}$ and transgranularly fractured with striation under the condition of $\phi_{c}<\phi_{f}$, and those at $750{ }^{\circ} \mathrm{C}$ were intergranularly fractured by the formation of cavity-type intergranular cracks at the interface between matrix and $\mathrm{M}_{23} \mathrm{C}_{6}$ or sigma phase on the grain boundaries. The same fracture modes were observed in the specimens ruptured in fatigue tests for the prior crept materials suggesting that the rupture life under combined creep-fatigue loadings was influenced by the microstructural intergranular damages during creep loading.

(4) The intergranular damage mode under combined creep-fatigue loadings corresponded to that obtained in constant loading creep tests under the condition of creep loading (temperature and creep stress) in the combined creep-fatigue loading test. It is expected from these results that the same relation between $\phi_{c}$ and $\phi_{f}$ is obtained, if the combined creepfatigue loading test is carried out under the condition of creep loading where the same intergranular damage mode, i.e., the same creep fracture mode is observed.

\section{REFERENCES}

1) ASME Boiler and Pressure Vessel Code, Section III, Division 1, Case N47-17, (1979).

2) D. P. Timo: Proc. Int'l. Conf. Thermal Stress and Thermal Fatigue, CEGB, Berkeley, (1969), 439.

3) K. H. Kloos, J. Granacher and P. Rieth: Arch. Eisenhüttenw., 52 (1981), 237.

4) R. M. Gurran and B. M. Wundt: Proc. 1976 ASME-MPC Symp. Creep-Fatigue Interaction, ASME, New York, (1976), 203.

5) H. Breitling, E. D. Großer and H. Lorenz: Arch. Eisenhüttenw., 48 (1977), 403.

6) D. Sidey: Mat. Sci. Eng., 33 (1978), 189.

7) K. Yagi, K. Kubo and C. Tanaka: J. Soc. Mat. Sci. Japan, 28 (1979), 400.

8) K. Yagi, K. Kubo and C. Tanaka: J.Soc. Mat. Sci. Japan, 29 (1980), 928.

9) K. Yagi, G. Tanaka and K. Kubo: J. Soc. Mat. Sci. Japan, 33 (1984), 1078.

10) K. Yagi, K. Kubo, C. Tanaka and T. Fukumoto: J. Soc. Mat. Sci. Japan, 22 (1973), 265.

11) K. Hirakawa, K. Tokimasa, K. Toyama, T. Yukitoshi and K. Yoshikawa: The Preprint of JSME Meeting, No. 7702, JSME, Tokyo, (1977), 218.

12) R. Lagneborg and R. Attermo: Met. Trans., 2 (1971), 1821.

13) K. Yagi, G. Tanaka, K. Kubo and H. Tanaka: J. Soc. Mat. Sci. Japan, 32 (1983), 556.

14) S. Taira: Creep in Structure, N. J. Hoff, ed., SpringerVerlag, (1962), 96.

15) J. T. Barnby: JISI, 204 (1966), 23.

16) D. G. Morris and D. R. Harries: Metal Sci., 12 (1978), 525.

17) D. J. McLean: J. Inst. Metals, 85 (1956/57), 468.

18) K. Yamaguchi and K. Kanazawa: J. Japan Inst. Metals, 40 (1976), 316. 